\title{
Editorial
}

\section{An open access-journal with a difference}

I have the great honour of kicking off the already $64^{\text {th }}$ volume of Journal of Geosciences (counting the predecessors also published by the Czech Geological Society, of course). I think we can be happy about the current

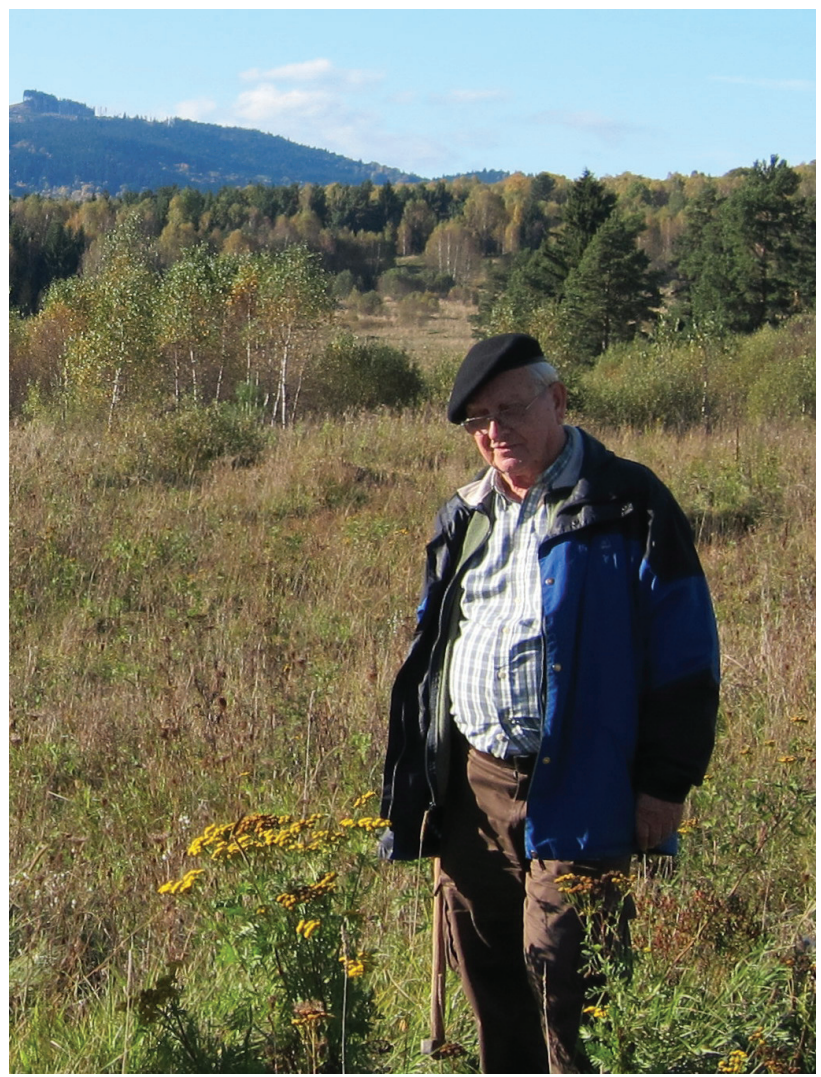

Photo of Stanislav Vrána taken by J. Pertoldová during field work in the Šumava Mts.
Journal's performance and can only promise to carry on in our mission of bringing you scientifically sound, processoriented and though-provoking reading from various branches of mineralogy, geophysics, hard-rock geology, petrology and geochemistry. We aim to do so under the open-access model but with a difference. Unlike the numerous publishers, ranging from honest to predatory, we do not take the open access as an excuse to maximize our profits. We try to keep nil to minimal costs to the authors, gratefully accepting the kind financial and logistic support from the Czech Geological Society, Council of Scientific Societies of the Czech Republic, Czech Geological Survey, Institute of Petrology and Structural Geology (Charles University in Prague) and Czech Literary Fund Foundation. Clearly, we could not do so without the tireless work and enthusiasm of our editorial board, as well as guest editors and reviewers, to whom I would like to extend my sincere thanks. Last but not least, I am indebted to our staff (executive editor M. Vaněček, web editor V. Erban, technical redactor I. Sedláčková and secretary T. Sidorinová) for their diligent work and patience with the impulsive and aging editor in chief.

This issue is very special because it opens with the last paper by Stanislav Vrána, valued colleague, friend and former editor-in-chief of our predecessor, Journal of the Czech Geological Society (1992-2006). Stanislav passed away more than a year ago, aged 82 years. But we need not to be sad - I can guarantee that also the current paper bears the typical imprint of Stanislav's work. Namely, it shows his deep knowledge of mineralogy and petrology, innovative thinking and thought-provoking ideas - for which we will Stanislav always remember! 
